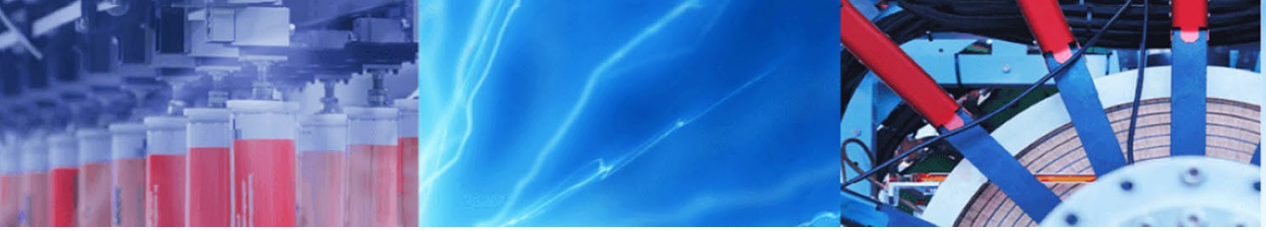

Research Article

\title{
2,2'-(2-Oxopropane-1,3-diyl)bis-(2-hydroxy-1H-indene-1,3(2H)-dione): synthesis, crystal, electronic and molecular docking studies
}

\author{
Raza Murad Ghalib ${ }^{1}$ - Syad Hasan Mehdi ${ }^{2} \cdot$ Tanveer Hasan $^{3}$ • Anoop Kumar Gupta ${ }^{4}$
}

(C) Springer Nature Switzerland AG 2019

\begin{abstract}
We have synthesized here a novel ninhydrin derivative 2,2'-(2-oxopropane-1,3-diyl)bis-(2-hydroxy-1H-indene-1,3(2H)-dione) (1) through a green and facile strategy with the use of acetic acid as catalyst. The structure has been determined by spectral analysis and by single crystal $\mathrm{X}$-ray analysis. This molecule contains two 2-hydroxy-1,3-indanedione moieties fused with 2-oxo-propane at 1 and 3 positions. The molecular structure of the title compound $\left(\mathrm{C}_{21} \mathrm{H}_{14} \mathrm{O}_{7}\right)$ has been optimized and the structural parameters have been calculated by DFT/B3LYP method using $6-311++G(d, p)$ basis set. The fundamental vibrational wave numbers and their intensities were calculated and a good agreement between observed FT-IR spectrum and scaled calculated wavenumbers has been achieved. The electronic properties of the molecule are discussed with the help of the descriptors such as HOMO-LUMO and MEPS. In addition, the molecular docking and NBO analyses are also carried out to get a better insight of the molecule.
\end{abstract}

Graphical abstract The major intermolecular interactions in the crystal structure are established through hydroxy group to carbonyl oxygen of the adjacent molecules by means of strong $\mathrm{O}-\mathrm{H} . . . \mathrm{O}$ hydrogen bonds leading to form a zigzag arrangement running along $b$-axis.

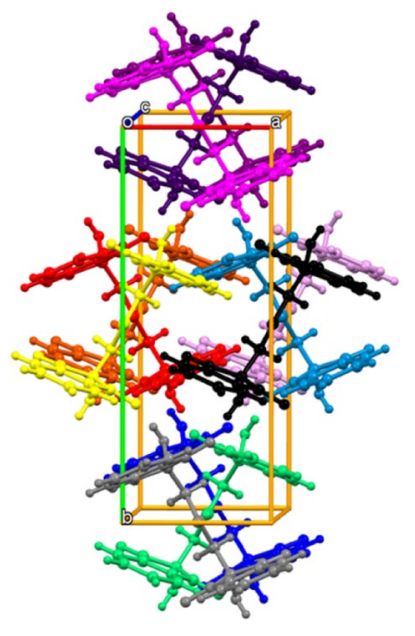

Keywords Ninhydrin · Crystal structure · HOMO-LUMO - Vibrational analysis · DFT · Molecular docking

Electronic supplementary material The online version of this article (https://doi.org/10.1007/s42452-019-0366-y) contains supplementary material, which is available to authorized users.

$\checkmark$ Raza Murad Ghalib, raza2005communications@gmail.com|'Department of Chemistry, Faculty of Sciences and Arts - Khulais, University of Jeddah, P.O. Box 355, Jeddah 21921, Kingdom of Saudi Arabia. ${ }^{2}$ Department of Chemistry, S. P. G College, Lucknow, India. ${ }^{3}$ Department of Physics, S. P. G College, Lucknow, India. ${ }^{4}$ Department of Chemistry, Indian Institute of Technology Kanpur, Kanpur, Uttar Pradesh 208016, India.

SN Applied Sciences (2019) 1:351 | https://doi.org/10.1007/s42452-019-0366-y

Received: 18 February 2019 / Accepted: 13 March 2019 / Published online: 20 March 2019 


\section{Introduction}

Ninhydrin is a common coloration reagent for amino acids and has been recounted as a useful compound in organic, analytical, forensic sciences and biochemical [1]. Ninhydrin was first synthesized in 1910 by Ruhemann [2], after that, various ninhydrin derivatives were synthesized and their chemical properties were investigated [3]. Ninhydrin can be considered as a tricarbonyl compound due to its equilibrium with indane-1,2,3-trione (Scheme 1) [4]. The middle carbon ( $\mathrm{C}-2$ position) of this trione is more electrophilic and easily available for nucleophiles. Furthermore, in ninhydrin, acid catalyzes the formation of reactive electrophilic species at C-2 position or make it is an electrophilic centre. Although the reaction of ninhydrin with amino acids and amines were studied by various groups, the reactions of ninhydrin with active methylene nucleophiles are scare [5]. In presence of acid, ninhydrin at C-2 position, form condensation abduct with a-carbon of carbonyls [6-9]. Previously, we have established a suitable one-pot method for preparing the ninhydrin derivative as 2-Acetonyl-2-hydroxyindan-1,3-dione [6, 10]. In continuation of our work, we are currently exploring the reactions of ninhydrin with ninhydrin derivative containing active methylene group. As part of our current program to synthesized novel ninhydrin derivatives, we have successfully synthesized this titled compound (1) by the reaction of ninhydrin with our previously reported ninhydrin

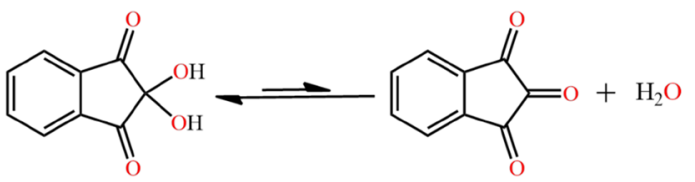

Ninhydrin

(2,2-dihydroxy-1,3-indandione) Indan-1,2,3-trione

Scheme 1 Equilibrium of ninhydrin with indane-1,2,3-trione derivative i.e. 2-Hydroxy-2-(2-oxo-propyl)-indane-1,3-dione $[5,6,10]$ (Scheme 2$)$. The equilibrium structure of the titled compound is obtained and the intramolecular interaction is studied by quantum theory of atoms in molecule. The vibrational spectral features of this compound have been explained and the spectrum calculated by the DFT/ B3LYP method using the $6-311++\mathrm{G}(d, p)$ basis set has been compared with the experimentally recorded FT-IR spectrum. In this regard, the VEDA 4 program has been used to carry out the potential energy distribution (PED) analysis $[13,14]$. This work also includes the analysis of HOMO, LUMO and the 3D molecular electrostatic potential surface (MEPS) analysis. We also studied the molecular docking of the title compound in HEME OXYGENASE $1(2 Z \mathrm{VU})$ protein to find its possible pharmacological importance. Based on our literature survey, we found that there are no reports on the title molecule.

\section{Experimental}

\subsection{Materials and physical measurements}

Reagent grade ninhydrin was obtained from SigmaAldrich and was used as received. All other chemicals and solvents were procured from S. D. Fine Chemicals and Merck, respectively and used without further purification. TLCs were taken on silica gel plates (silica gel $60 \mathrm{~F}_{254}$ on aluminium foil, Merck). Infrared spectrum was recorded on a PerkinElmer Model 1320 spectrometer (KBr disk, 400-4000 $\mathrm{cm}^{-1}$ ). The ${ }^{1} \mathrm{H}$ NMR and ${ }^{13} \mathrm{C}$ NMR spectra were recorded on a Bruker Avance spectrometer $(600 \mathrm{MHz}$ for ${ }^{1} \mathrm{H}$ NMR and $150 \mathrm{MHz}$ for ${ }^{13} \mathrm{C}$ NMR) in DMSO- $d_{6}$ and chemical shifts are reported in ppm. The following abbreviations are used: $m$ (multiplet), $s$ (singlet), brs (broad singlet). The mass spectrum was recorded on Waters Q-Tof PremierHAB213 mass spectrometer in ionization mode. Elemental analyses was performed with a Perkin-Elmer 240 analyzer.

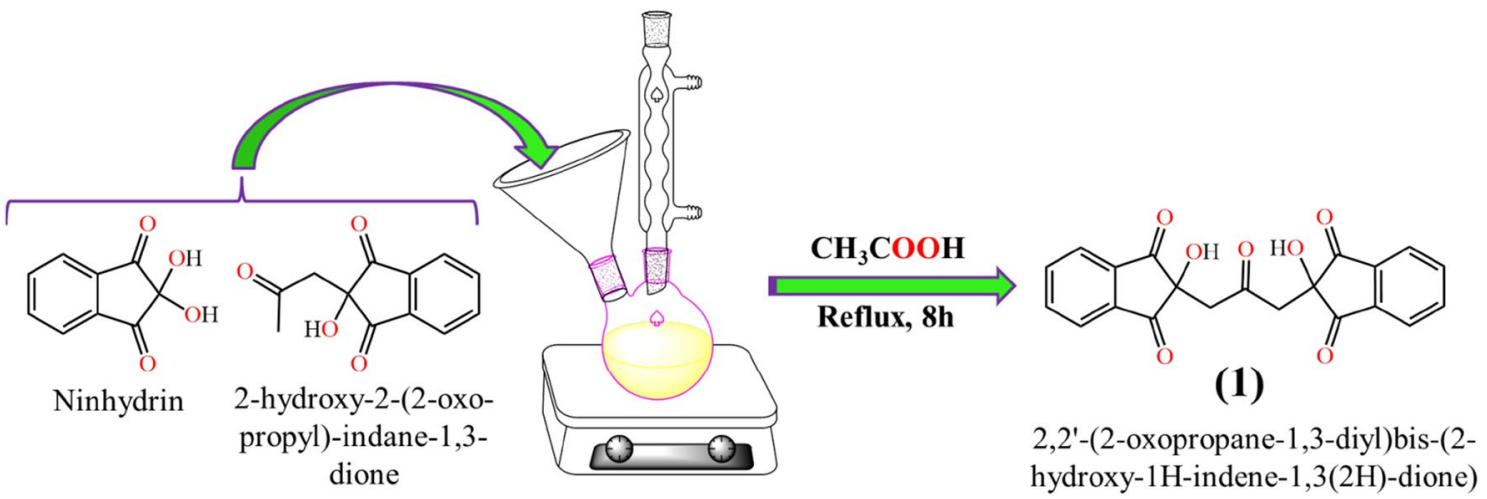

Scheme 2 Synthesis of compound 1 i.e. 2,2'-(2-oxopropane-1,3-diyl)bis-(2-hydroxy-1H-indene-1,3(2H)-dione) 
The melting point was taken on Stuart SMP30 digital melting point apparatus by open capillary method and is uncorrected.

\subsection{Synthesis of the title compound 1}

A mixture of ninhydrin $(1.78 \mathrm{~g}, 10 \mathrm{mmol})$ and 2-Hydroxy2-(2-oxo-propyl)-indane-1,3-dione $(2.18 \mathrm{~g}, 10 \mathrm{mmol})$ were stirred and refluxed in $50 \mathrm{ml}$ of acetic acid for $8 \mathrm{~h}$. The conversion was monitored by TLCs and after completion of the reaction; the reaction mixture was dried on rotary evaporator at low pressure. The crude product was crystallized with chloroform-alcohol $(1: 1 \mathrm{v} / \mathrm{v})$ to give the translucent crystals of titled compound 1. Yield $2.31 \mathrm{~g} \mathrm{(60 \% );} \mathrm{m.p.} 150{ }^{\circ} \mathrm{C}, \mathrm{Rf}=0.27$ (hexane/acetone, 1:1); IR (KBr): $v_{\max }=3421,2913,2850,1750,1707,1599,1385$, 1317, 1294, $1266 \mathrm{~cm}^{-1}$ (Fig. S2). ${ }^{1} \mathrm{H}$ NMR $(600 \mathrm{MHz}$, DMSO$\left.d_{6}, \delta\right):=3.34(\mathrm{~s}, 2 \mathrm{H},>\mathrm{CH} 2), 3.36(\mathrm{~s}, 2 \mathrm{H},>\mathrm{CH} 2), 6.69$ (brs, $2 \mathrm{H}$, $\mathrm{OH}), 7.86-7.90(\mathrm{~m}, 8 \mathrm{H}, \mathrm{ArH}) \mathrm{ppm}$ (Fig. S3). ${ }^{13} \mathrm{C}$ NMR and DEPT-135 (150 MHz, DMSO- $\left.d_{6,} \delta\right): 45.59$ (2 X CH2), 73.20 (2 X - C-OH), $122.95(4 \times \mathrm{CH}), 135.82(4 \mathrm{X} \mathrm{CH}), 139.57(4 \mathrm{X}$ C), $197.93(4 \times C=0), 205.63(C=0)$ ppm (Fig. S4, S5). MS (EI): $\mathrm{m} / \mathrm{z} 378.0696\left[\mathrm{M}^{+}\right]$((Fig. S7); Elemental anal. Calcd. for $\mathrm{C}_{21} \mathrm{H}_{14} \mathrm{O}_{7}$ (378.06): $\mathrm{C}, 66.67 ; \mathrm{H}, 3.73 ; \mathrm{O}, 29.60 \%$; Found: $\mathrm{C}$, $66.54 ; \mathrm{H}, 3.67 ; \mathrm{O}, 29.57 \%$.

\subsection{Computational methods}

The molecular structure of titled compound (1) is modeled by the Gaussview program package 5.0.8 [15] and shown in Fig. 1 of the SI. All quantum chemical calculations of the title compound are carried out on an Intel Core I3(TM) CPU/4.20 GHz laptop computer using Gaussian 09 program package, invoking gradient geometry optimization and employing the B3LYP/6-311++G $(d, p)$ levels of theory to predict the molecular structure and vibrational wave numbers [16].

\subsection{X-ray structural studies}

The crystal data for 1 has been collected on a Bruker APEXII CCD diffractometer equipped with a graphite monochromator and $\mathrm{Mo}-\mathrm{Ka}(\lambda=0.71073 \AA, 140 \mathrm{~K})$ radiation. The program SMART ${ }^{1}$ was used for collecting frames of data, indexing reflections, and determining lattice parameters; SAINT [17] for integration of the intensity of reflections and scaling; SADABS [18] for absorption correction; and SHELXTL $[19,20]$ for space group and structure determination and least-squares refinements on F2. The crystal structure was solved and refined by full-matrix least-squares methods against $\mathrm{F} 2$ by using the program SHELXL-2014 [21] and Olex-2 software [22]. All the non-hydrogen atoms were refined with anisotropic displacement parameters.

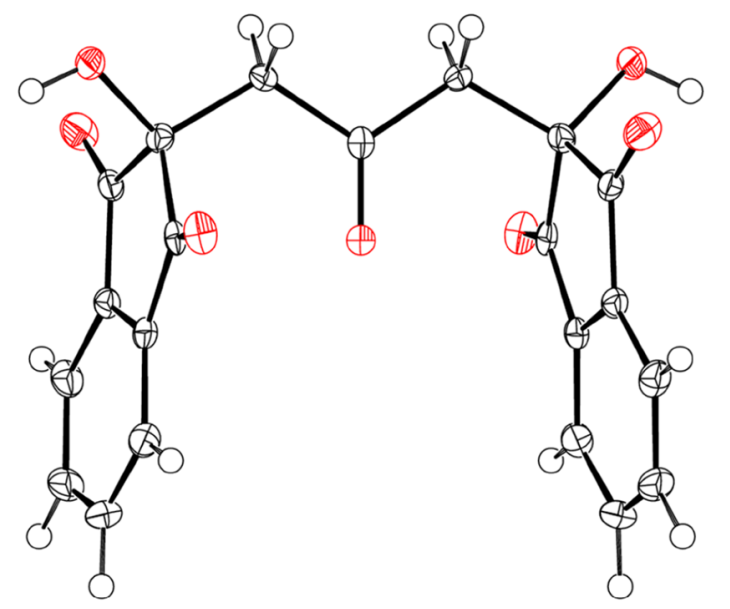

Fig. 1 Ortep-view of the 2,2'-(2-oxopropane-1,3-diyl)bis-(2-hydroxy-1H-indene-1,3(2H)-dione). The thermal ellipsoids are drawn at $50 \%$ probability level

Hydrogens positions were fixed at calculated positions and refined isotropically. Lattice parameters, data collection and refinement parameters are summarized in Table 1 and selected bond distances and bond angles are given in Table S2 of supplementary data. Crystallographic data for the structure reported in this paper have been deposited with the Cambridge Crystallographic Data Center number, CCDC 1831708. Copies of this information may be obtained free of charge on application to CCDC, 12 Union Road, Cambridge CB2 1EZ, UK (fax: +44 1223336 033; e-mail: deposit@ ccdc.cam.ac.uk or http://www.ccdc. cam.ac.uk).

\section{Results and discussion}

\subsection{Chemistry}

The C-2 of indane-1,2,3-trione (ninhydrin) is much more electrophilic and this is why it reacts readily with nucleophiles. In presence of acid, it protonates the hydroxyl group in ninhydrin that causes elimination of water molecule to produce a reactive electrophilic species; a C-2 carbocation [7]. In our previous study, we reported the synthesis of 2-Hydroxy-2-(2-oxo-propyl)-indane1,3-dione in excellent yield [6]. Title molecule $\mathbf{1}$ was synthesized in $60 \%$ yield by the reaction of ninhydrin with 2-Hydroxy-2-(2-oxo-propyl)-indane-1,3-dione [6] in acetic acid medium. 2-Hydroxy-2-(2-oxo-propyl)indane-1,3-dione in acetic acid form a carbon based nulcleophile which attacks on electrophilic $\mathrm{C}-2$ position of ninhydrin to form condensation product (Scheme 1) [8, 9]. In this reaction, a new $\mathrm{C}-\mathrm{C}$ bond is formed between 
Table 1 Crystallographic and Structure Refinement Data for 1

\begin{tabular}{|c|c|}
\hline Parameters & 1 \\
\hline Empirical formula & $\mathrm{C}_{21} \mathrm{H}_{14} \mathrm{O}_{7}$ \\
\hline Formula wt & 378.32 \\
\hline Crystal system & Orthorhombic \\
\hline Space group & $1 b a 2$ \\
\hline$a, \AA$ & $6.1608(9)$ \\
\hline$b, \AA$ & 16.395 \\
\hline$c, \AA$ & $16.395(2)$ \\
\hline$a(\mathrm{deg})$ & 90.00 \\
\hline$\beta$ (deg) & 90.00 \\
\hline$\gamma($ deg $)$ & 90.00 \\
\hline$V, \AA^{3}$ & $1656.0(3)$ \\
\hline$Z$ & 4 \\
\hline$\rho_{\text {calc }} \mathrm{g} / \mathrm{cm}^{3}$ & 1.517 \\
\hline$\mu, \mathrm{mm}^{-1}$ & 0.115 \\
\hline Temperature $\left({ }^{\circ} \mathrm{K}\right)$ & $100(2)$ \\
\hline$\theta \max$ & 28.33 \\
\hline$F(000)$ & 784 \\
\hline Refl. collected & 11,530 \\
\hline Independent refl. & 2053 \\
\hline GOOF & 0.974 \\
\hline $\begin{array}{l}\text { Final } R \text { indices } \\
{[I>2 \sigma(I)]}\end{array}$ & $\begin{array}{l}\mathrm{R} 1=0.0386 \\
w^{\mathrm{R} 2}=0.0935\end{array}$ \\
\hline $\begin{array}{l}R \text { indices } \\
\text { (all data) }\end{array}$ & $\begin{array}{l}\mathrm{R} 1=0.0454 \\
w^{\mathrm{R} 2}=0.0976\end{array}$ \\
\hline
\end{tabular}

C-2 of ninhydrin and methyl carbon of 2-oxo-propyl in 2-Hydroxy-2-(2-oxo-propyl)-indane-1,3-dione.

The structure of compound $\mathbf{1}$ was assigned based on the IR (Fig. S2), ${ }^{1} \mathrm{H}$ NMR (Fig. S3), ${ }^{13} \mathrm{C}$ NMR (Fig. S4), DEPT135 (Fig. S5), C-H HSQC (Fig. S6), mass spectra (Fig. S7), elemental analysis and single crystal $x$-ray analysis. In the IR spectra of compound $\mathbf{1}$, the $\mathrm{OH}$ absorption bands appeared at $3421 \mathrm{~cm}^{-1}$. Weak bands at $3070 \mathrm{~cm}^{-1}$ and $1599 \mathrm{~cm}^{-1}$ confirmed aromatic $\mathrm{C}-\mathrm{H}$ and $\mathrm{C}=\mathrm{C}$ stretchings. The band at $2913 \mathrm{~cm}^{-1}$ was assigned to the $\mathrm{C}-\mathrm{H}$ stretching vibrations of the methylene groups. The intense bands at 1750 and $1707 \mathrm{~cm}^{-1}$ were assigned to the $>C=O$ vibrations in indane rings \& condensed 2-oxypropyl moiety. In the ${ }^{1} \mathrm{H}$ NMR spectrum of title molecule, four protons as singlet at $\delta 3.36 \mathrm{ppm}$ were assigned for two $-\mathrm{CH}_{2}$. This four-proton singlet at $\delta 3.36$ correlates with ${ }^{13} \mathrm{C}$ peak at $\delta 45.59 \mathrm{ppm}$ in HSQC; which goes negative in dept-135 spectrum and confirmed as two methylenes. Two multiplets integrating for four protons each at $\delta 7.86-7.88$ and 7.88-7.90 ppm clearly show expected aromatic protons on two indane moieties of 1. These two multiplets correlate in $\mathrm{HSQC}$ with ${ }^{13} \mathrm{C}$ peaks at $\delta 122.95$ and $135.82 \mathrm{ppm}$, those gone positive in dept135 spectrum and confirmed as aromatic-CHs. One broad singlet at $\delta 6.69 \mathrm{ppm}$ integrating for two protons indicated

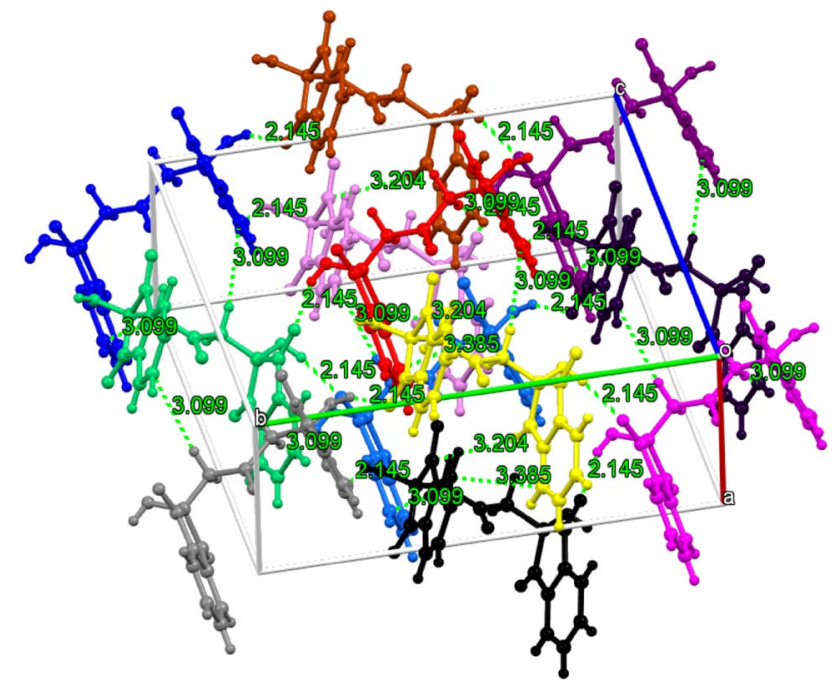

Fig. 2 Packing diagram of the compound 1 showing hydrogen bonding and weak non-classical contacts. Each color corresponds to compound 1

two $\mathrm{OH}$ groups. The desired signal for two tertiary carbons attached with $\mathrm{OH}$; falls on $\delta 71.16 \mathrm{ppm}$. The ${ }^{13} \mathrm{C}$ signals at $\delta 205.63(\mathrm{C}=\mathrm{O})$ and $197.93(4 \mathrm{C}=\mathrm{O})$ are absent in dept-135 and correlating with no proton in HSQC, that confirm them as five carbonyl carbons. The ${ }^{13} \mathrm{C}$ signal in aromatic at $\delta$ 139.57 (4C) is absent in dept-135 and correlating with no proton in HSQC and assigned as aromatic tertiary carbons. Along with all desired peaks, it clearly indicates the formation of condensation product between ninhydrin and 2-Hydroxy-2-(2-oxo-propyl)-indane-1,3-dione.

\subsection{Crystal structure analysis}

The single crystal $X$-ray structural study revealed that the compound $\mathbf{1}$ crystallizes in orthorhombic space group Iba 2 with half of molecule in the asymmetric unit. An ORTEP diagram of the compound $\mathbf{1}$ is shown in Fig. 1 , indicating the presence of 2-oxopropane moiety $(\mathrm{C}-\mathrm{O}$ :

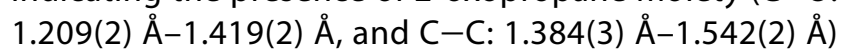
which is flanked on both side by the 2-hydroxy-1H-indene-1,3(2H)-dione moiety. The planes of the 2-hydroxy$1 \mathrm{H}$-indene-1,3(2H)-dione moiety and 2-oxopropane moiety are approximately orthogonal to each other (inter-planar angle $=82.29^{\circ}$ ). The bond lengths and bond angle of the titled compound is present within the expected ranges for ninhydrin derivatives [10]. Figure 2 demonstrates the crystal packing of compound 1 which is stabilized by hydrogen bonding and some weak, non-classical contacts $[11,12]$ viz. $\pi \cdots \pi, C-H \cdots \pi$, and lone pair... in nature. The strong hydrogen bonding is observed between $\mathrm{O}(002)-\mathrm{H} \cdots \mathrm{O}(003)$, with interatomic distance 

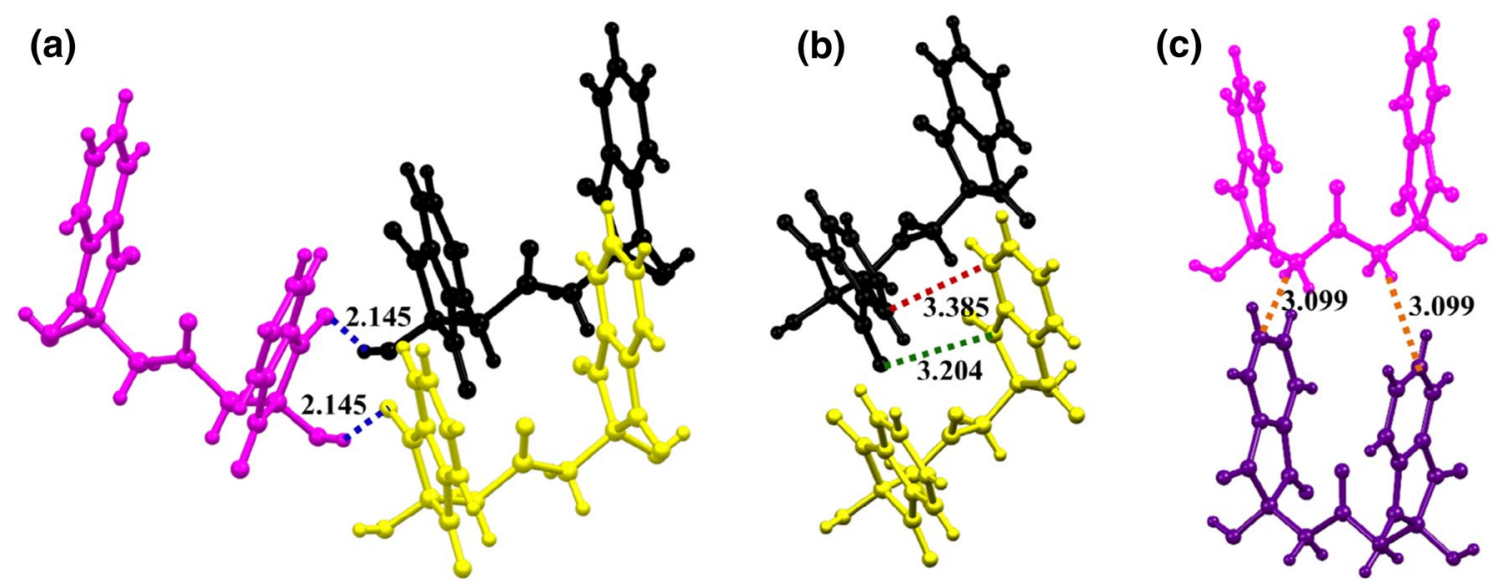

Fig. 3 Crystal packing of the compound 1, showing the perspective view of a O-H...O hydrogen bonding, $\mathbf{b} \pi \cdots \pi$ and $\mathrm{O} \cdots \pi$ contacts, and $\mathbf{c}$ $\mathrm{C}-\mathrm{H} \cdots \mathrm{m}$ contacts. Each color corresponds to compound 1

of 2.145(3) $\AA$ (Fig. 3a) where as the weak non-classical: [1] $\pi \cdots \pi$ and $O(004) \cdots \pi$ contacts are observed between $\mathrm{C}(00 \mathrm{C}) \cdots \mathrm{C}(00 \mathrm{C})$ and $\mathrm{O}(004) \cdots \mathrm{C}(00 \mathrm{~B})$, with interatomic distances of 3.385(2) $\AA$ and 3.204 (3) $\AA$, respectively (Fig. 3b), and [2] C-H $\cdots \pi$ contact is observed between $\mathrm{C}(00 \mathrm{~A})-\mathrm{H} \cdots \mathrm{C}(00 \mathrm{D})$ with interatomic distance of 3.099 (4) $\AA$ (Fig. 3C). The major intermolecular interactions in the crystal structure are established through hydroxy group to carbonyl oxygen of the adjacent molecules by means of strong $\mathrm{O}-\mathrm{H}$... O hydrogen bonds leading to form a zigzag arrangement running along $b$-axis, as depicted in Fig. 4. These zigzag arrangements in the single layer are propagates through $\mathrm{C}(00 \mathrm{C}) \ldots \mathrm{C}(00 \mathrm{C})$ and $\mathrm{O}(004) \ldots \mathrm{C}(00 \mathrm{~B})$ contacts to form a $2 \mathrm{D}$ supramolecular layers. Each 2D supramolecular layers are further connected through $\mathrm{C}(00 \mathrm{~A})-\mathrm{H}$...C $(00 \mathrm{D})$ contacts to form overall crystal lattice.

\subsection{Vibrational analysis}

In a nonlinear molecule, number of normal modes of vibrations, are $(3 \mathrm{~N}-6)$, where $\mathrm{N}$ is the number of atoms $[23,24]$. The title compound (1) contains 42 atoms and hence exhibits 120 normal modes of vibrations. The Gaussview 5.0.8 program package is used for the assignment of calculated frequencies which provides a $3 D$ view of the vibrational modes VEDA 4 software program is used to calculate the potential energy distribution (PED). An empirical uniform scaling factor of 0.983 up to $1700 \mathrm{~cm}^{-1}$ and 0.958 for above $1700 \mathrm{~cm}^{-1}$ were used to correct the overestimations of the calculated harmonic frequencies $[25,26]$. All the vibrational assignments are presented in table $\mathrm{S} 1$.
Fig. 4 View of a the crystal lattice of compound $\mathbf{1}$, and $\mathbf{b}$ showing the zigzag arrangement running along $b$-axis. Each color corresponds to compound 1 (a)

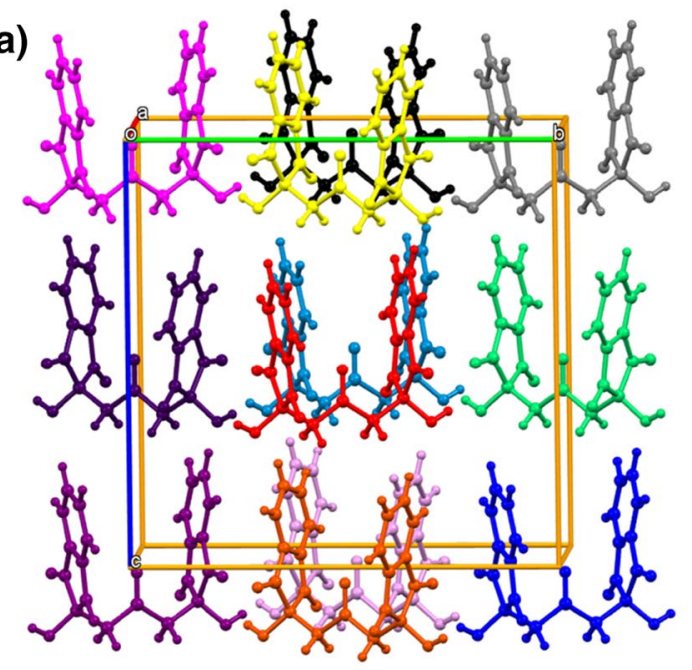

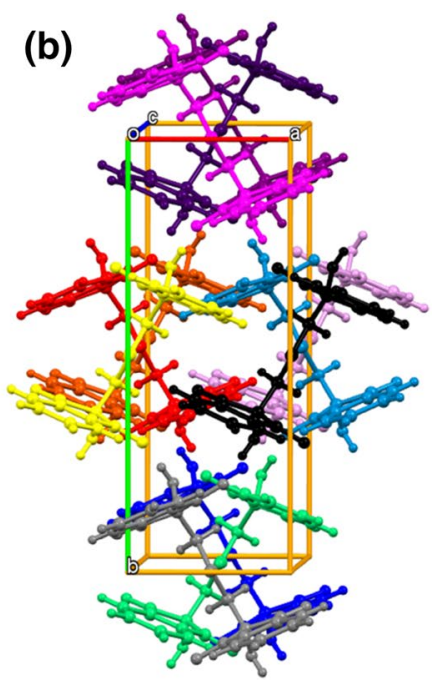

SN Applied Sciences 


\subsection{1 $\mathrm{O}-\mathrm{H}$ stretching}

(O-H) stretching appears generally at $3600-3400 \mathrm{~cm}^{-1}$ [27]. In the FTIR spectrum of the title molecule (Fig S2) a very strong absorption peak is observed at $3421 \mathrm{~cm}^{-1}$ and this mode is calculated at $3501 \mathrm{~cm}^{-1}$ with $100 \%$ PED.

\subsection{2 (C-H) stretching}

The characteristic region for the $(\mathrm{C}-\mathrm{H})$ stretching is $3100-2900 \mathrm{~cm}^{-1}$. A weak absorption peak is observed at $2913 \mathrm{~cm}^{-1}$ which is assigned to six calculated frequencies obtained at 3104, 3094, 3081, 3068, 3015 and $2958 \mathrm{~cm}^{-1}$. The $(\mathrm{C}-\mathrm{H})$ in plane bending modes are useful for characterization and they appear as strong band in the FTIR spectrum at frequency peaks 1385, 1334, 1317, 1294, $1266 \mathrm{~cm}^{-1}$ and are well assigned well with calculated frequencies.

\subsection{3 $(\mathrm{C}=0)$ Stretching}

This stretching mode makes the skeleton of the compound as rigid and the formation of hydrogen bond checks the charge distribution in the ring and side chains. In the present study this mode is observed with two strong peaks at $1750 \& 1707 \mathrm{~cm}^{-1}$ in the FTIR spectrum and are calculated at $1736 \& 1621 \mathrm{~cm}^{-1}$ by DFT/B3LYP method. It is in good agreement with the reported literature which is in the range $1750-1630 \mathrm{~cm}^{-1}$ [28].

\subsection{4 (C-C) stretching}

The semicircle aromatic stretching $(\mathrm{C}-\mathrm{C})$ gives rise to characteristics bands in the spectral range $1600-1000 \mathrm{~cm}^{-1}$ [29]. In this study this vibrational mode is calculated in the range $1583-886 \mathrm{~cm}^{-1}$ and spectral peaks for these modes are observed at 1599, 138, 1334, 1266, 1179, 1078 and $969 \mathrm{~cm}^{-1}$ in the FTIR spectrum. The corresponding in plane bending and torsional modes were found to be consistent with the recorded spectral values.

\subsection{5 (C-0) stretching}

The $(\mathrm{C}-\mathrm{O})$ stretching along with bending and torsional modes, are calculated in the range $1115-705 \mathrm{~cm}^{-1}$ and is well matched with literature [29].

\subsubsection{Low frequency vibrational modes}

In the study of weak intermolecular interactions which generally occurs in enzyme reactions, study lower frequency vibrations play vital role [30]. It is also helpful in the interpretation of the reaction of electromagnetic radiation on biological systems [31]. In the present study, several out of plane modes mixed with torsional modes are calculated in the range $700-50 \mathrm{~cm}^{-1}$ and these are observed in the form of three peaks observed at 692 , 567 , and $500 \mathrm{~cm}^{-1}$ in the FTIR spectrum.

\subsection{Electronic properties}

The frontier molecular orbitals (HOMO and LUMO) participate in chemical reactions and their energy gap decides the intensity of the chemical reactivity and stability of a compound [32]. A molecule with small energy band gap is more polarizable and generally possesses high chemical reactivity and low kinetic stability and is termed as soft molecule $[33,34]$. In this study the plots of LUMO and HOMO are shown in Fig. 5 and their values are given in table S1. From 2D plot, it is evident that the entire HOMO is spread on the benzene rings and penta rings in increasing order. The $2 \mathrm{D}$ plot of LUMO $(-2.7265 \mathrm{eV})$ of the title molecule shows that LUMO is uniformly distributed on benzene rings and penta rings. Unlike HOMO, small amount of LUMO is also spread on backbone atoms $\mathrm{O} 2, \mathrm{O} 1, \mathrm{C} 11$ and $\mathrm{C} 6$ in decreasing order. The frontier orbital gap is calculated as $2.2271 \mathrm{eV}$ for the title molecule. The molecular electrostatic potential surface (MEPS) is shown in Fig. 6 with color scale ranging from -4.001 to +4.001 a.u for the title molecule. MEPS displays the molecular shape, size and electrostatic potential values in terms of color coding which is a useful tool for the correlation between molecular structure and physiochemical properties of the molecules $[35,36$, 37].
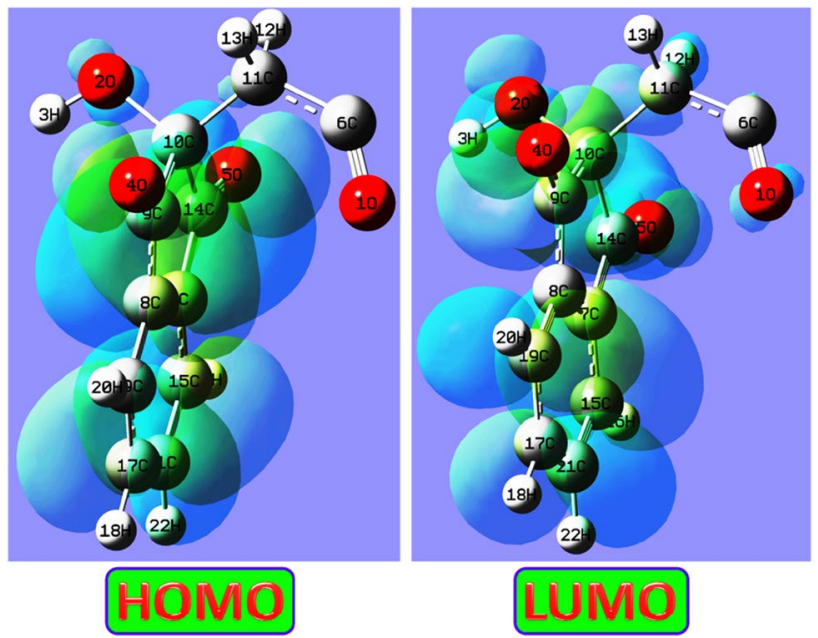

Fig. 5 2D plot of HOMO-LUMO of compound 1 as seen by Gaussview 5.0.8 


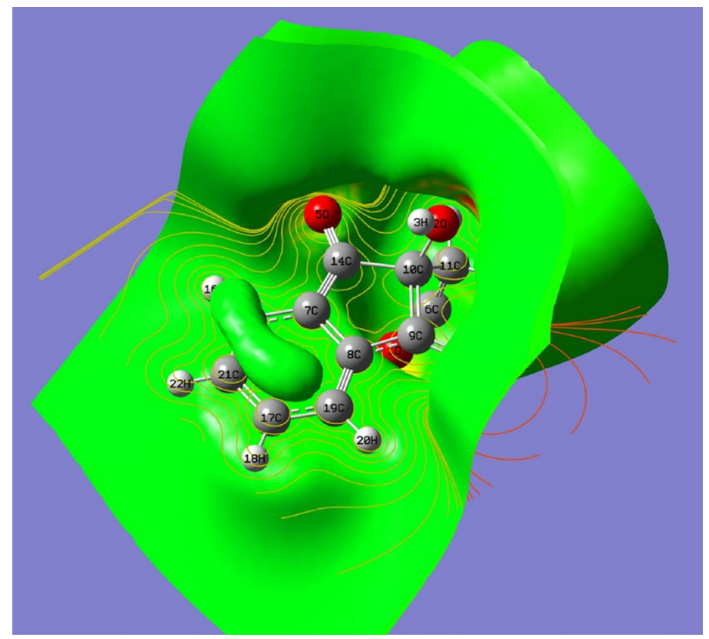

Fig. 6 2D plot of MEPS of compound 1 as seen by Gaussview 5.0.8

\subsection{Molecular docking}

The process of molecular docking decides the manner in which two molecules, like a drug (ligand) and a receptor (protein), fit to each other and it inhibits its function and thus behaves effectively as a drug [38]. Initially using Pass 10 evaluation professional package we choose the structure which is most resemble with our title molecule and by considering the anticarcenogenic activity we select the gene HEME OXYGENASE 1. The data in pdb format of the target protein has been obtained from the protein data bank (PDB) [39] database with PDBID = (2ZVU). In the present theoretical study the inhibition of HEME OXYGENASE 1 (2ZVU) with the title compound $\left(\mathrm{C}_{21} \mathrm{H}_{14} \mathrm{O}_{7}\right)$, molecular docking study has been carried out using Hex program 8.0. Figure 7 shows the docked conformation of the protein $2 Z \mathrm{ZU}$ with the binding site of the target ligand. The docking method is a model which provides the binding affinity of a particular site in terms of the e-value. Larger the negative e-value the better the docking is. In present study total e-value calculated from Hex program is -182.42 for HEME OXYGENASE 1(2ZVU) protein, which indicates that the title compound $\left(\mathrm{C}_{21} \mathrm{H}_{14} \mathrm{O}_{7}\right)$ can inhibit the protein HEME OXYGENASE 1(2ZVU).

\section{Conclusion}

The optimized molecular geometry, vibrational wavenumbers, electronic parameters of the title compound, 2,2'-(2-oxopropane-1,3-diyl)bis-(2-hydroxy-1H-indene$1,3(2 \mathrm{H})$-dione) have been calculated using DFT B3LYP method adopting 6-311++G(d,p) basis set. A good agreement between experimental and calculated normal modes of vibrations has been achieved. The frontier orbital energy

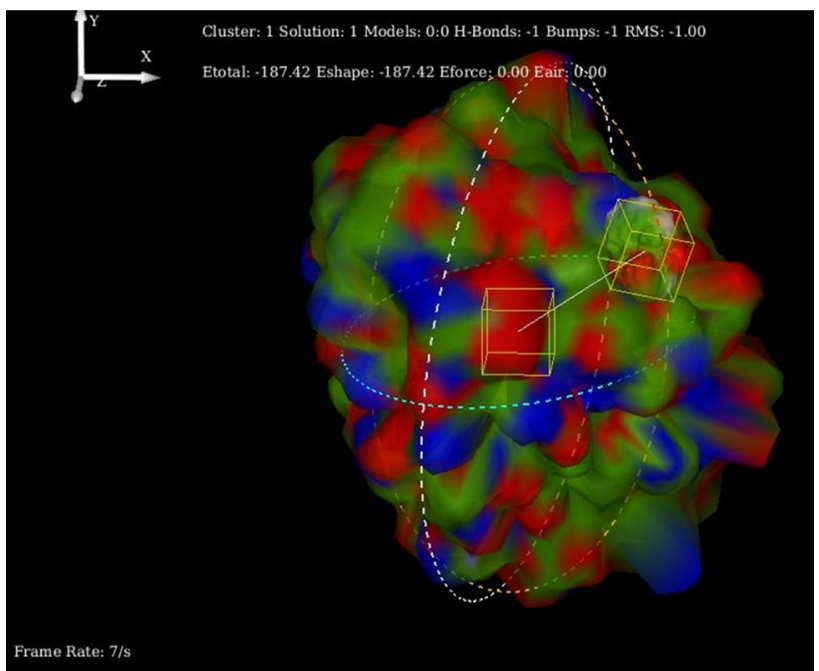

Fig. 7 2D Docking structure of HEME OXYGENASE 1(2ZVU) with compound 1

gap is calculated as 2.2271. The results of molecular docking studies speculate that this biologically active molecule $\left(\mathrm{C}_{21} \mathrm{H}_{14} \mathrm{O}_{7}\right)$ might serve as a potential candidate for the inhibition to protein "HEME OXYGENASE 1(2ZVU)" thereby indicating its possible pharmacological importance.

Acknowledgements We would like to acknowledge Faculty of Sciences and Arts-Khulais, University of Jeddah, Jeddah, Kingdom of Saudi Arabia for research facilities.

\section{Compliance with ethical standards}

Conflict of interest The authors report no conflict of interest.

\section{References}

1. Joullie MM, Thompson TR, Nemeroff NH (1991) Ninhydrin and ninhydrin analogs syntheses and applications. Tetrahedron 47:8791-8830

2. Ruhemann S (1910) CXXXII.-Cyclic di- and tri-ketones. J Trans Chem Soc 97:1438-1449

3. Hansen DB, Madeleine MJ (2005) The development of novel ninhydrin analogues. Chem Soc Rev 34:408-417

4. Herath AMC, Rajapakse RMG, Karunarathne V, Wicramasinghe A (2006) Electrochemical investigation of superoxide anion scavenging ability of 1, 2, 3-triketohydrindene hydrate in aprotic solvents. Electrochim Acta 51:2890-2897

5. Kneubuhler S, Carta V, Altomare C, Carotti A, Testa B (1993) Synthesis and monoamine oxidase inhibitory activity of 3-Substituted 5H-Indeno[1,2- c]pyridazines. Helv Chim Acta 76:1956-1963

6. Ghalib RM, Hashim R, Sulaiman O, Jawad A, Mehdi SH, Bogdanovic GA, Trifunovic SR, Kawaruma F, Ahamed BMK, Majid AMSA (2017) Green synthesis of novel class of benzazocine derivatives, their crystal structures and anticancer activity. Curr Org Synth $14: 127-136$ 
7. Das S, Pramanik A, Fröhlich R, Patra A (2004) Facile acid-catalyzed condensation of 2-hydroxy-2,2'-biindan-1,1',3,3'-tetrone with phenols, methoxyaromatic systems and enols. Tetrahedron 60:10197-10205

8. Chakrabarty M, Mukherji A, Arima S, Harigaya Y, Pilet G (2009) Expeditious reaction of ninhydrin with active methylene compounds on montmorillonite K10 clay. Monatsh Chem 140:189-197

9. Klumpp DA, Fredrick S, Lau S, Jin KK, Bau R, Surya Prakash GK, Olah GA (1999) Acid-catalyzed condensations of ninhydrin with aromatic compounds. preparation of 2,2-Diaryl-1,3-indanediones and 3-(Diarylmethylene)isobenzofuranones. J Org Chem 64:5152-5155

10. Fun H-K, Quah CK, Parveen M, Ghalib RM, Mehdi SH (2009) 2-Acetonyl-2-hydroxy-indan-1,3-dione. Acta Cryst E 65:01209

11. Cossar PJ, Russell CC, McCluskey SN, Pope D, Bernhardt PV, McCluskey A (2018) Crystal structure of ethyl 2,4-dimethyl1-phenyl-6-thioxo-1,6-dihydropyrimidine-5-carboxylate: the product from the reaction of ethyl 3-aminocrotonate, phenylisothiocyanate and acetic anhydride. J Chem Crystallogr 48:91-95

12. Mendez IJL, Pleizier JS, Wang HB, Wisner JA (2018) The Structure of Cis-2,2'-Azopyridine in the Solid State. J Chem Crystallogr. https://doi.org/10.1007/s10870-018-0737-z

13. Jamroz MH (2004) Vibrational energy distribution analysis, VEDA 4 program. Warsaw, Poland

14. Jamroz MH (2013) Vibrational energy distribution analysis (VEDA): scopes and limitations. Spectrochim Acta Mol Biomol Spectrosc 114:220-230

15. Frisch E, Hratchian HP, Dennington RD II, Keith TA, Millam J, Neilsen B, Holder AJ, Hiscocks J (2009) Gaussview, version 508, vol 235. Gaussian Inc, Wallingford

16. Frisch MJ, Trucks GW, Schlegel HB, Scuseria GE, Robb MA, Cheeseman JR, Scalmani G, Barone V, Mennucci B, Petersson GA, Nakatsuji H, Caricato M, Li X, Hratchian HP, Izmaylov AF, Bloino J, Zheng G, Sonnenberg JL, Hada M, Ehara M, Toyota K, Fukuda R, Hasegawa J, Ishida M, Nakajima T, Honda Y, Kitao O, Nakai H, Vreven T, Montgomery JJA, Peralta JE, Ogliaro F, Bearpark M, Heyd $J$ J, Brothers E, Kudin KN, Staroverov VN, Kobayashi R, Normand J, Raghavachari K, Rendell A, Burant JC, lyengar SS, Tomasi J, Cossi M, Rega N, Millam JM, Klene M, Knox JE, Cross JB, Bakken V, Adamo C, Jaramillo J, Gomperts R, Stratmann RE, Yazyev O, Austin AJ, Cammi R, Pomelli C, Ochterski JW, Martin RL, Morokuma K, Zakrzewski VG, Voth GA, Salvador P, Dannenberg JJ, Dapprich S, Daniels AD, Farkas O, Foresman JB, Ortiz JV, Cioslowski J, Fox DJ (2009) Gaussian 09, revision A. 02. Gaussian Inc, Wallingford

17. SMART \& SAINT (2003) Software reference manuals, version 6.45. Bruker Analytical X-ray Systems, Inc., Madison

18. Sheldrick GM (2002) SADABS a software for empirical absorption correction; version 2.05; program for empirical absorption correction of area detector data. University of Göttingen, Göttingen

19. SHELXTL (2000) Reference manual, version 6.1. Bruker Analytical Xray Systems Inc., Madison

20. Sheldrick GM (2001) SHELXTL v.6.12. Bruker AXS Inc., Madison

21. Sheldrick GM (2008) A short history of SHELX. Acta Crystallogr A 64:112-122
22. Dolomanov OV, Bourhis LJ, Gildea RJ, Howard JAK, Puschmann $\mathrm{H}$ (2009) OLEX2: a complete structure solution, refinement and analysis program. J Appl Cryst 42:339-341

23. Silverstein RM, Bassler GC, Morrill TC (1991) Spectrometric identification of organic compounds. John Wiley and sons, Hoboken

24. Socrates $G$ (2001) Infrared, Raman characteristic group frequencies-tables, charts, 3rd edn. Wiley, New York

25. Karabacak M, Kurt M, Cinar M, Coruh A (2009) Experimental (UV, NMR, IR and Raman) and theoretical spectroscopic properties of 2-chloro-6-methylaniline. Mol Phys 107(3):253-264

26. Sundaraganesan N, Ilakiamani S, Saleem H, Wojciechowski PM, Michalska D (2005) FT-Raman and FT-IR spectra, vibrational assignments and density functional studies of 5-bromo-2-nitropyridine. Spectrochim Acta A 61:2995-3001

27. Biradar NS, Kulkarni VK (1971) Spectroscopic study of tin(IV) complexes with multidentate Schiff bases. J Inorg Nucl Chem 33:3781-3786

28. Ruddick JNR, Sames JR (1973) Mössbauer and infrared spectroscopic studies of some organotin(IV) schiff base complexes. J Organometal Chem 60:233-246

29. Colthup NB, Daly LH, Wiberley SE (1964) Introduction to infrared, Raman Spectroscopy. Academic Press, New York, pp 74-315

30. Chou KC (1984) Biological functions of low-frequency vibrations (phonons). III. Helical structures and microenvironment. Biophys J 45:881-889

31. Frohlich $\mathrm{H}$ (1988) In biological coherence and response to external stimuli. Springer, Berlin

32. Sklenar H, Jager J (1979) Molecular structure-biological activity relationships on the basis of quantum-chemical calculations. Int J Quantum Chem 16:467-484

33. Fleming I (1976) In frontier orbitals and organic chemical reactions. Wiley, Hoboken

34. Sajan D, Joseph L, Vijayan N, Karabacak M (2011) Natural bond orbital analysis, electronic structure, non-linear properties and vibrational spectral analysis of I-histidinium bromide monohydrate: a density functional theory. Spectrochim Acta A 81:85-98

35. Murray JS, Sen K (1996) In molecular electrostatic potentials: concepts and applications. Elsevier, Amsterdam

36. Alkorta I, Perez JJ (1996) Molecular polarization potential maps of the nucleic acid bases. Int J Quant Chem 57:123-135

37. Karabacak M, Cinar M (2012) FT-IR, FT-Raman, UV spectra and DFT calculations on monomeric and dimeric structure of 2-amino-5-bromobenzoic acid. Spectrochim Acta A 86:590-599

38. Srivastava V, Kumar A, Mishra BN, Siddiqui MI (2008) Molecular docking studies on DMDP derivatives as human DHFR inhibitors. Bioinformation 4:180-188

39. Available from, http://www.rcsb.org/pdb/explore.do?structurel $D=2 Z V U$

Publisher's Note Springer Nature remains neutral with regard to jurisdictional claims in published maps and institutional affiliations. 